\title{
PBN Derivative OKN-007
}

National Cancer Institute

\section{Source}

National Cancer Institute. PBN Derivative OKN-007. NCI Thesaurus. Code C102983.

A disulfonyl derivative of phenyl-tert-butyl nitrone (PBN), with potential anti-glioma activity. Although the exact mechanism(s) of action of OKN007 are still largely unknown, this agent appears to inhibit cancer cell proliferation and migration. This agent appears to inhibit the activity of sulfatase 2 (SULF2), a highly specific endog lucosamine-6-sulfatase that is overexpressed in the extracellular matrix of cancer cells and catalyzes the removal of sulfate from the 6-O-sulfate esters of heparin. In addition, OKN007 may induce changes in tumor metabolism and scavenge free radicals. 